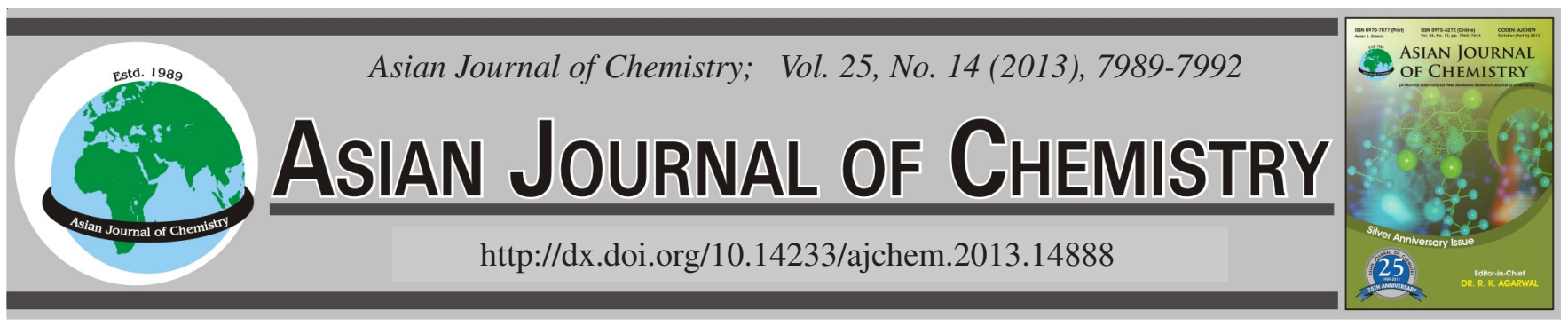

\title{
On-line Spectrophotometric Method for Decolourizing Reaction Kinetics of Reactive Black 5 by Fenton Oxidation
}

\author{
HANG $\mathrm{Xu}^{*}$ and GUOZHI LI
}

Chemical Engineering and Pharmaceutics School, Henan University of Science and Technology, Luoyang 471023, P.R. China

*Corresponding author: Tel: +86 379 63180121; E-mail: xhinbj@126.com

(Received: 3 December 2012;

Accepted: 29 July 2013)

AJC-13856

Fenton oxidation was employed to treat and decolourize the modeling wastewater of reactive black 5 by online spectrophotometry. The
effects of initial $\mathrm{FeSO}_{4}$ dosage, initial $\mathrm{H}_{2} \mathrm{O}_{2}$ dosage, $\mathrm{pH}$ value, initial reactive black 5 and temperature on the colour removal and decolourizing
reaction rate constant were investigated. The results show that Fenton oxidation follows pseudo first order kinetics in the first stage and reaction
activation energy is $3.451 \mathrm{~kJ} \mathrm{~mol}^{-1}$. The optimum initial $\mathrm{H}_{2} \mathrm{O}_{2}$ and $\mathrm{pH}$ was $2.118 \mathrm{mM}$ and 3, respectively. Initial $\mathrm{FeSO}_{4}$ dosage against $\mathrm{k}_{\mathrm{ap}}$
presents a linear correlation: $\mathrm{k}_{\mathrm{ap}}=0.1354\left[\mathrm{Fe}^{2+}\right]_{\mathrm{o}}$. Intrinsic reaction rate constant of reactive black 5 and ${ }^{`} \mathrm{OH}$ is $7.528 \times 10^{11} \mathrm{M}^{-1} \mathrm{~s}^{-1}$.

Key Words: Fenton oxidation, Reactive black 5, Kinetics, Reaction rate constant.

ᄂ - - - - - - - - - - - - - - - - - - - - - - - - -

\section{INTRODUCTION}

Dyestuff brings our life beautiful. Therefore it is wideranging applied in the many industries. In recent report, each year about $12 \%$ of synthetic textile dyes were lost during producing processes ${ }^{1}$. A large part of them directly discharged to the environment without any treatment. Wastewater in dye and textile industry had strong colour, high COD and a relatively low BOD/COD ratio $^{2}$. Nowadays, there are many approaches to deal with colouring wastewater, such as biodegradation, chemical coagulation, photocatalytic oxidation and chemical oxidation, etc.

Fenton's reagent is a classical water treatment technology in chemical oxidation. It is a mixture of $\mathrm{Fe}^{2+}$ catalyst and hydrogen peroxide $\left(\mathrm{H}_{2} \mathrm{O}_{2}\right)$ to form hydroxyl radicals $\left({ }^{\wedge} \mathrm{OH}\right)$ to oxidize contaminants in acid aqueous ${ }^{3}$. The ${ }^{\wedge} \mathrm{OH}$ serves as very powerful, effective and nonspecific oxidizing agent, second only to fluorine in oxidizing powder ${ }^{4}$ to destruct chemical structure of organic. The mechanism of Fenton oxidation process could be described as some complex redox reactions in eqs. (1)-(6) in treatment of dye (D).

In this study, Fenton's reagent was employed to treat modeling compound of textile wastewater of reactive black 5 by online spectrophotometric system ${ }^{5}$. The purpose of this research is to find out the best reaction condition for maximum colour removal and reaction rate in dyeing wastewater and established the kinetic model of dyeing degradation during Fenton oxidation process.

$\mathrm{Fe}^{2+}+\mathrm{H}_{2} \mathrm{O}_{2} \stackrel{\mathrm{k}_{1}}{\longrightarrow} \mathrm{Fe}^{3+}+\bullet \mathrm{OH}+\mathrm{OH}^{-}, \mathrm{k}_{1}=76 \mathrm{M}^{-1} \mathrm{~s}^{-1}$

$$
\mathrm{D}+\bullet \mathrm{OH} \stackrel{\mathrm{k}_{2}}{\longrightarrow} \mathrm{D}_{\text {oxid }}
$$

$\mathrm{Fe}^{2+}+\bullet \mathrm{OH} \stackrel{\mathrm{k}_{3}}{\longrightarrow} \mathrm{Fe}^{3+}+\mathrm{OH}^{-}, \mathrm{k}_{3}=3.2 \times 10^{8} \mathrm{M}^{-1} \mathrm{~s}^{-1}$

$\mathrm{H}_{2} \mathrm{O}_{2}+\bullet \mathrm{OH} \stackrel{\mathrm{k}_{4}}{\longrightarrow} \bullet \mathrm{OOH}+\mathrm{H}_{2} \mathrm{O}, \mathrm{k}_{4}=1.0 \times 10^{10} \mathrm{M}^{-1} \mathrm{~s}^{-1}$

$\bullet \mathrm{OH}+\bullet \mathrm{OOH} \stackrel{\mathrm{k}_{5}}{\longrightarrow} \mathrm{H}_{2} \mathrm{O}+\mathrm{O}_{2}, \mathrm{k}_{5}=2.7 \times 10^{7} \mathrm{M}^{-1} \mathrm{~s}^{-1}$

$\mathrm{Fe}^{3+}+\mathrm{H}_{2} \mathrm{O}_{2} \stackrel{\mathrm{k}_{6}}{\longrightarrow} \mathrm{Fe}^{2+}+\mathrm{H}^{+}+\bullet \mathrm{OOH}, \mathrm{k}_{6}=0.01 \mathrm{M}^{-1} \mathrm{~s}^{-1}(6)$

\section{EXPERIMENTAL}

Reactive black 5 was obtained from Jiangsu Shenxin Dye Company (China) and used without further purification. Modeling wastewater of reactive black 5 was prepared by dissolving requisite quantity of the dyestuffs in double distilled water. $\mathrm{FeSO}_{4} \cdot 7 \mathrm{H}_{2} \mathrm{O}, \mathrm{H}_{2} \mathrm{SO}_{4}$ and $\mathrm{H}_{2} \mathrm{O}_{2}\left(30 \%\right.$ in $\left.\mathrm{H}_{2} \mathrm{O}\right)$ were of analytical grade and purchased from Beijing Chemical Reagent Company.

Fig. 1 shows online spectrophotometric system. This system can be integrated by three parts i.e., reaction unit, optical measuring unit and recording unit. Reaction unit contains a magnetic stirrer apparatus (Rongsheng Instrument company, China), thermometer, $250 \mathrm{~mL}$ beaker and temperature controller. Magnetic stirrer apparatus has another function of heating solution. Optical measuring unit includes UV-visible spectrometer, peristaltic pump and current colourimetric container (UNICO 2012PC, Shanghai, China). Current velocity of wastewater in system is $18.5 \mathrm{~mL} \mathrm{~L}^{-1}$. Recording unit is a computer and monitoring frequency is $6 \mathrm{~min}^{-1}$.

Fenton oxidation process was performed using $200 \mathrm{~mL}$ solution, which contained specified concentration of selected 


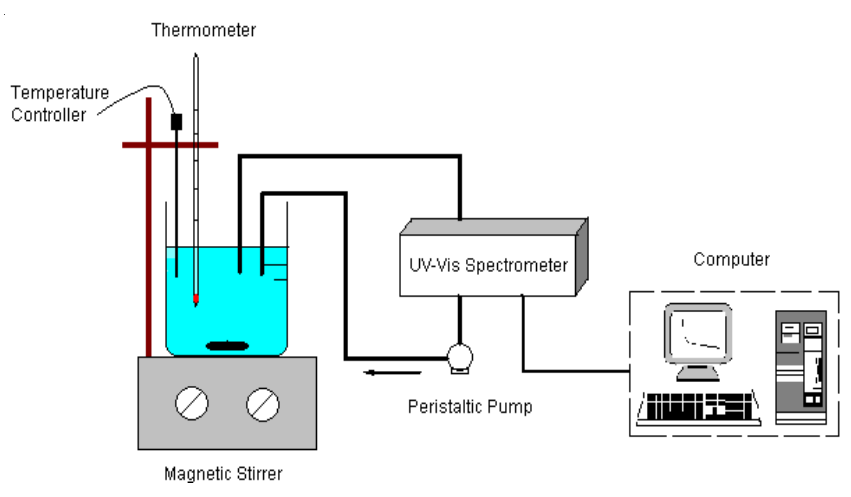

Fig. 1. Online spectrophotometric system

dyestuff in beaker. The calculated $\mathrm{FeSO}_{4}$ concentration and $\mathrm{pH}$ adjustment using $\mathrm{H}_{2} \mathrm{SO}_{4}$ were added to the wastewater. At the same time, stir and pump were applied. Wastewater was pressed into the UV-visible spectrophotometer by peristaltic pump. The maximal absorption peak of reactive black 5 was $599 \mathrm{~nm}$ monitored by UV-visible spectrophotometer. When the calculated $\mathrm{H}_{2} \mathrm{O}_{2}$ concentrations were added into the wastewater and computer which was linked with spectrophotometer began to record instant absorbance.

\section{RESULTS AND DISCUSSION}

In many early reports, Fenton oxidization process apparently followed first-order kinetics ${ }^{6,7}, \ln \left(\mathrm{C}_{0} / \mathrm{C}\right)=\mathrm{k}_{\mathrm{ap}} \mathrm{t}$. The slope $\mathrm{k}_{\mathrm{ap}}$ is the decolourizing reaction rate constant. In this paper, the $k_{a p}$ is one of the important parameters to evaluate degradation efficiency. Another parameter was the colour removal (R) in $300 \mathrm{~s}$ :

$$
\mathrm{R}=\frac{\mathrm{C}_{0}-\mathrm{C}_{300}}{\mathrm{C}_{0}} \times 100 \%
$$

Time-dependent degradation of reactive black 5: The change in $\mathrm{C} / \mathrm{C}_{0}$ value of dyes versus irradiation time is shown in Fig. 2. C represents the concentration of dye in $\mathrm{tsec}$ and $\mathrm{C}_{0}$ is the initial concentration. Fenton oxidation process can be prepared by two regions to treat reactive black 5 from Fig. 2 . At beginning of the reaction $(\mathrm{t} \geq 50 \mathrm{~s})$, decolourization is faster and in the second region ( $t \geq 50 \mathrm{~s}$ ), decolourizing rate is significantly retarded as the reaction time is extended. These experimental phenomena

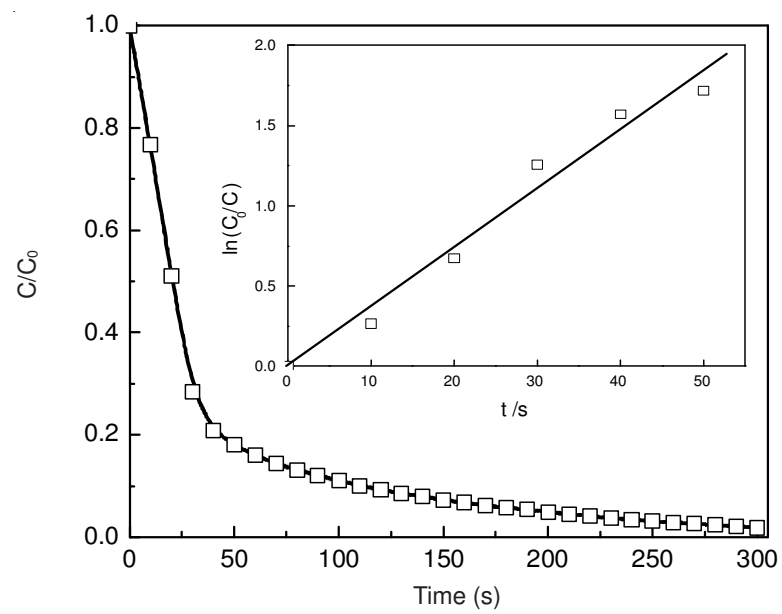

Fig. 2. Time-dependent degradation of reactive black $5\left([\mathrm{RB} 5]_{\mathrm{o}}=17 \mathrm{mg} / \mathrm{L}\right.$, $\left.\left[\mathrm{Fe}^{2+}\right]_{\mathrm{o}}=0.09711 \mathrm{mM},\left[\mathrm{H}_{2} \mathrm{O}_{2}\right]_{\mathrm{o}}=2.118 \mathrm{mM}, \mathrm{pH}=3, \mathrm{~T}=15^{\circ} \mathrm{C}\right)$ can be explained by two aspects. Decrement of $\mathrm{Fe}^{2+}$ and $\mathrm{H}_{2} \mathrm{O}_{2}$ concentration can decrease the reaction rate during Fenton process. In another way, intermediate products during the Fenton oxidation process engage in the reaction and restrain mainly reaction to proceed. From the Fig. 2, Fenton oxidization process apparently follows first-order kinetics in the early stage.

Effect of initial $\mathrm{Fe}^{2+}$ dosage: A series of $\mathrm{Fe}^{2+}$ dosage influence on $\mathrm{R}$ and $\mathrm{k}_{\mathrm{ap}}$ has been investigated in Fig. 3. The $\mathrm{R}$ increases from $74.1 \%$ to $95.22 \%$ with the addition of $\mathrm{Fe}^{2+}$ dosage from 0.03237 to $0.09711 \mathrm{mM}$. However R was only $96.10 \%$ when $\mathrm{Fe}^{2+}$ catalyst is improved $0.1618 \mathrm{mM}$. This experimental phenomenon suggests that high $\mathrm{Fe}^{2+}$ dosage does not effect decolourization of reactive black 5 in the Fenton oxidation process due to $\mathrm{Fe}^{2+}$ ion competing ' $\mathrm{OH}$ with dye molecules ${ }^{8}$, which can be expressed by the eqn. 3 . Therefore, $0.09711 \mathrm{mM}$ of initial $\mathrm{Fe}^{2+}$ dosage can be used as an optimum dosage. Initial $\mathrm{Fe}^{2+}$ dosage against $\mathrm{k}_{\text {ap }}$ shows a linear correlation from the Fig. $3, \mathrm{k}_{\mathrm{ap}}=0.1354\left[\mathrm{Fe}^{2+}\right]_{\mathrm{o}}, \mathrm{R}^{2}=0.9917$. This result expresses that $\mathrm{Fe}^{2+}$ as a catalyst can accelerate the decomposition of $\mathrm{H}_{2} \mathrm{O}_{2}$ obviously and produce ${ }^{\wedge} \mathrm{OH}$.

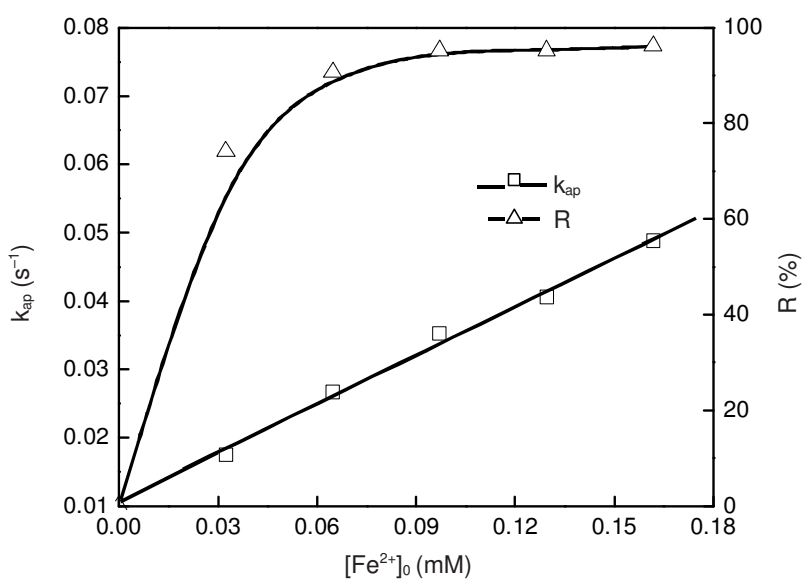

Fig. 3. Influence of initial $\mathrm{Fe}^{2+}$ concentration; $\left([\mathrm{RB} 5]_{\mathrm{o}}=17 \mathrm{mg} / \mathrm{L},\left[\mathrm{H}_{2} \mathrm{O}_{2}\right]_{\mathrm{o}}\right.$ $=2.118 \mathrm{mM}, \mathrm{pH}=3, \mathrm{~T}=15^{\circ} \mathrm{C}$ )

Effect of initial $\mathrm{H}_{2} \mathrm{O}_{2}$ dosage: Another important point considered in Fenton oxidation was the amounts of hydrogen peroxide ${ }^{9}$. Fig. 4 shows the change of $\mathrm{R}$ and $\mathrm{k}_{\mathrm{ap}}$ with various amounts of initial $\mathrm{H}_{2} \mathrm{O}_{2}$. The $\mathrm{R}$ and $\mathrm{k}_{\text {ap }}$ increase from 92.01

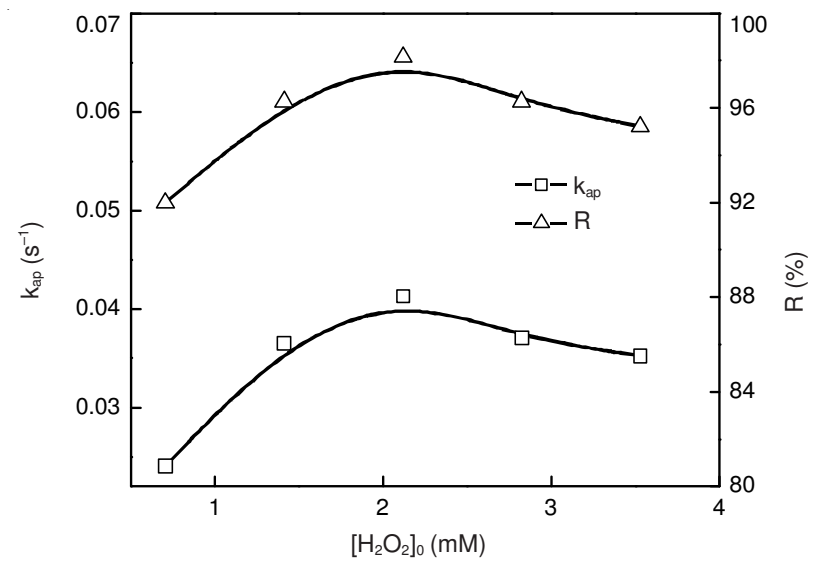

Fig. 4. Influence of initial $\mathrm{H}_{2} \mathrm{O}_{2}$ concentrations; ([RB 5 $]_{0}=17 \mathrm{mg} / \mathrm{L},\left[\mathrm{Fe}^{2+}\right]_{\mathrm{o}}$ $=0.09711 \mathrm{mM}, \mathrm{pH}=3, \mathrm{~T}=15^{\circ} \mathrm{C}$ ) 
to $98.17 \%$ and 0.0241 to $0.0413 \mathrm{~s}^{-1}$ respectively with the dosage of $\mathrm{H}_{2} \mathrm{O}_{2}$ from $0.7060 \mathrm{mM}$ to $2.118 \mathrm{mM}$. Further increasing $\mathrm{H}_{2} \mathrm{O}_{2}$ dosage to $3.529 \mathrm{mM}$, the $\mathrm{R}$ and $\mathrm{k}_{\text {ap }}$ decrease to $95.22 \%$ and $0.03525 \mathrm{~s}^{-1}$, respectively. Thus, the $2.118 \mathrm{mM}$ of initial $\mathrm{H}_{2} \mathrm{O}_{2}$ dosage can be used as the optimum dosage. The increase of $\mathrm{H}_{2} \mathrm{O}_{2}$ dosage accelerated the produce of ${ }^{\wedge} \mathrm{OH}$. However, $\mathrm{H}_{2} \mathrm{O}_{2}$ of higher concentration could adsorb ${ }^{\wedge} \mathrm{OH}$ (eqn. 4 and eqn. 5), as a result of reducing rate of $\mathrm{H}_{2} \mathrm{O}_{2}$. The more concentration of $\mathrm{H}_{2} \mathrm{O}_{2}$, the more power adsorbed function ${ }^{10}$.

Effect of pH: The $\mathrm{pH}$ of the solution plays an important role on decolourizing of dyes using Fenton oxidation ${ }^{11}$. The influence of $\mathrm{pH}$ on decomposition of reactive black 5 by Fenton oxidation is shown in Fig. 5. Three is the optimum $\mathrm{pH}$ from the Fig. 3. At low $\mathrm{pH}(\mathrm{pH}<3)$ the colour removal and reaction rate was limited because ${ }^{\wedge} \mathrm{OH}$ is consumed by the excessive $\mathrm{H}^{+}$as eqn. 8. When $\mathrm{pH}$ higher than 3 , Fenton oxidizing ability is decreased, not only by the decomposition of $\mathrm{H}_{2} \mathrm{O}_{2}$ but also the deactivation of the ferrous catalyst with the formation of ferric hydroxo complexes ${ }^{12}$ and the reduction of ${ }^{\wedge} \mathrm{OH}$ (eqn. 1) according to the Le Châtelier principle, which should be taken into consideration.

$$
\cdot \mathrm{OH}+\mathrm{H}^{+}+\mathrm{e}^{-} \rightarrow \mathrm{H}_{2} \mathrm{O}
$$

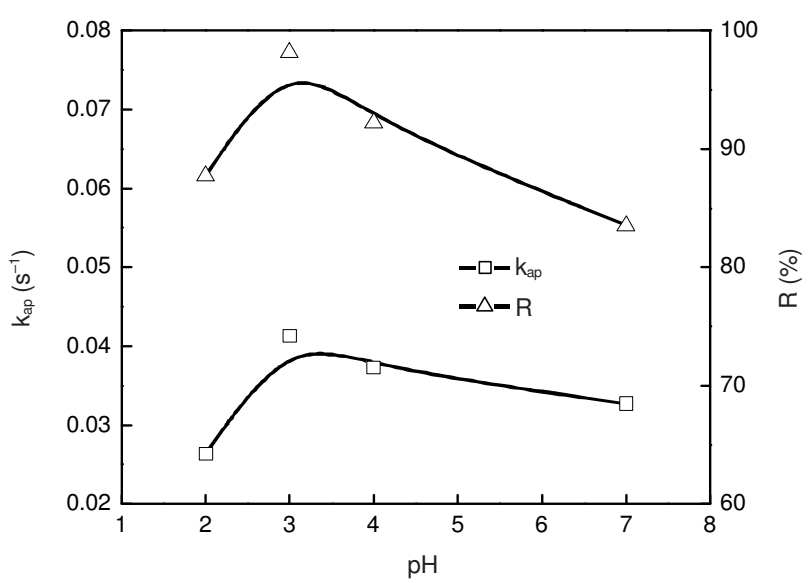

Fig. 5. Influence of $\mathrm{pH} ;\left([\mathrm{RB} 5]_{0}=17 \mathrm{mg} / \mathrm{L},\left[\mathrm{Fe}^{2+}\right]_{0}=0.09711 \mathrm{mM},\left[\mathrm{H}_{2} \mathrm{O}_{2}\right]_{\mathrm{o}}\right.$ $\left.=2.118 \mathrm{mM}, \mathrm{T}=15^{\circ} \mathrm{C}\right)$

Effect of temperature: Temperature is a key parameter impacting on the reaction rate and the product yield. Fig. 6 shows the $\mathrm{k}_{\text {ap }}$ increases from 0.0365 to $0.04088 \mathrm{~s}^{-1}$ with the

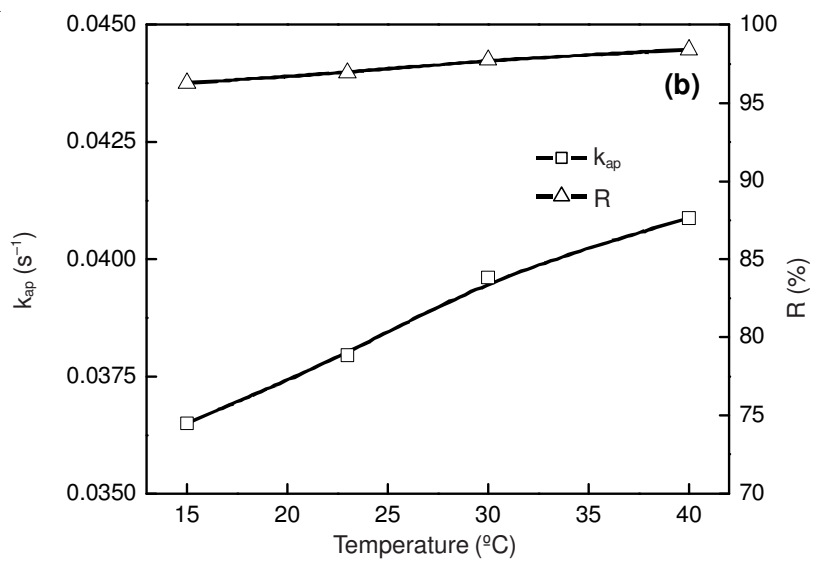

Fig. 6. Influence of temperature; $\left([\mathrm{RB} 5]_{\mathrm{o}}=17 \mathrm{mg} / \mathrm{L},\left[\mathrm{Fe}^{2+}\right]_{\mathrm{o}}=0.09711\right.$ $\mathrm{mM},\left[\mathrm{H}_{2} \mathrm{O}_{2}\right]_{\mathrm{o}}=1.412 \mathrm{mM}, \mathrm{pH}=3$ ) rise of temperature from 15 to $40^{\circ} \mathrm{C}$. However, the R presents only a little increase from 96.27 to $98.41 \%$. This result demonstrated that higher temperature increases the reaction rate between $\mathrm{Fe}^{2+}$ and $\mathrm{H}_{2} \mathrm{O}_{2}$, therefore increasing the rate of production of oxidizing species such as ${ }^{\wedge} \mathrm{OH}$ or high-valence iron species. However, the quantity of oxidizing agent $\left(\mathrm{H}_{2} \mathrm{O}_{2}\right)$ does not increase and $\mathrm{Fe}^{2+}$ is easily hydrolyzed while $\mathrm{H}_{2} \mathrm{O}_{2}$ is very unstable and decomposed by itself in higher temperature. Therefore the colour removal has not a big change with the rise of temperature. According to Arrhenius formula $\left(\ln \mathrm{k}_{\mathrm{ap}}=-\frac{\mathrm{Ea}}{\mathrm{RT}}+\ln \mathrm{A}\right)$, the dependence of $\ln \mathrm{k}_{\mathrm{ap}}$ on $-1 / \mathrm{T}^{13}$ can be linear fit to calculate the activation energy $\left(\mathrm{E}_{\mathrm{a}}\right)$ in the similar temperature range. The $\mathrm{E}_{\mathrm{a}}$ is $3.451 \mathrm{~kJ} \mathrm{~mol}^{-1}\left(\mathrm{R}^{2}>0.99\right)$.

Kinetics study: According to the reference ${ }^{14}$, relationship between initial $\mathrm{H}_{2} \mathrm{O}_{2}$ concentration and initial reactive black 5 concentration is as follow:

$$
\begin{gathered}
\frac{\left[\mathrm{H}_{2} \mathrm{O}_{2}\right]_{0}}{\mathrm{k}_{\mathrm{ap}}}=\mathrm{K}[\mathrm{D}]_{0}+\mathrm{B} \\
\mathrm{B}=\frac{\mathrm{k}_{3}}{\mathrm{k}_{1} \mathrm{k}_{2}}+\frac{2 \mathrm{k}_{4}\left[\mathrm{H}_{2} \mathrm{O}_{2}\right]_{0}}{\mathrm{k}_{1} \mathrm{k}_{2}\left[\mathrm{Fe}^{2+}\right]_{0}}
\end{gathered}
$$

The result shows in Fig. 7 about the linear relationship between $\frac{\left[\mathrm{H}_{2} \mathrm{O}_{2}\right]_{0}}{\mathrm{k}_{\mathrm{ap}}}$ and $[\mathrm{RB} 5]_{0}\left(\mathrm{R}^{2}>0.99\right)$. According to the intercept $(\mathrm{B})$, calculated intrinsic rate constant $\left(\mathrm{k}_{2}\right)$ of reactive black 5 and ${ }^{\wedge} \mathrm{OH}$ is $7.528 \times 10^{11} \mathrm{M}^{-1} \mathrm{~s}^{-1}$. From the Fig. 7, it is observed that the lower dyes concentration, the higher $k_{\text {ap }}$ for degradation process. The rise of dye concentration in aqueous increased the number of dye molecules in the water but ${ }^{\wedge} \mathrm{OH}$, so the colour removal and reaction rate $\left(\mathrm{k}_{\mathrm{ap}}\right)$ decreases.

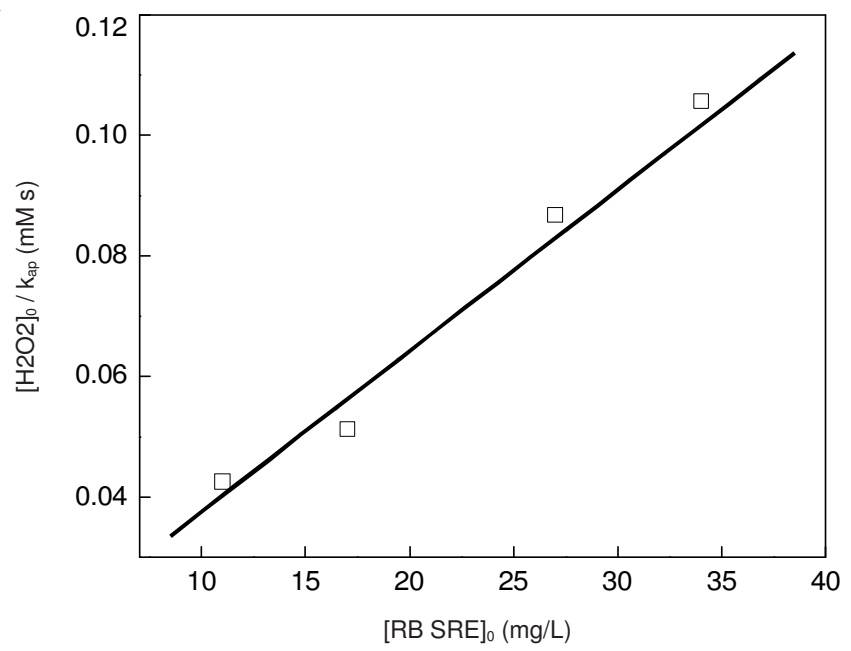

Fig. 7. Relationship between $\left[\mathrm{H}_{2} \mathrm{O}_{2}\right]_{\circ} / \mathrm{k}_{\text {ap }}$ and $[\mathrm{RB} 5]_{0} ;\left(\left[\mathrm{Fe}^{2+}\right]_{\mathrm{o}}=0.09711\right.$ $\mathrm{mM},\left[\mathrm{H}_{2} \mathrm{O}_{2}\right]_{0}=2.118 \mathrm{mM}, \mathrm{pH}=3, \mathrm{~T}=15^{\circ} \mathrm{C}$ )

\section{Conclusion}

Fenton oxidation process can rapidly deal with modeling wastewater of reactive black 5 and follows pseudo first order kinetics in the first stage. The optimum initial $\mathrm{H}_{2} \mathrm{O}_{2}$ and $\mathrm{pH}$ was $2.118 \mathrm{mM}$ and 3, respectively. Initial $\mathrm{FeSO}_{4}$ concentration 
against $\mathrm{k}_{\mathrm{ap}}$ presents a linear correlation: $\mathrm{k}_{\mathrm{ap}}=0.1354\left[\mathrm{Fe}^{2+}\right]_{\mathrm{o}}$. The reaction activation energy of Fenton oxidation is $3.451 \mathrm{~kJ} \mathrm{~mol}^{-1}$ and intrinsic rate constant of reactive black 5 and ${ }^{\wedge} \mathrm{OH}$ is 7.528 $\times 10^{11} \mathrm{M}^{-1} \mathrm{~s}^{-1}$.

\section{REFERENCES}

1. L.C. Morais, O.M. Freitas, E.P. Gonçalves, L.T. Vasconcelos and C.G González Beça, Water Res., 33, 979 (1999).

2. D.E. Kritikos, N.P. Xekoukoulotakis, E. Psillakis and D. Mantzavinos, Water Res., 41, 2236 (2007).

3. M.S. Lucas and J.A. Peres, Dyes Pigments, 71, 236 (2006)

4. P. Bautista, A.F. Mohedano, M.A. Gilarranz, J.A. Casas and J. Rodriguez, J. Hazard. Mater., 143, 128 (2007)
5. Y. Coque, E. Touraud and O. Thomas, Dyes Pigments, 54, 17 (2002).

6. E.G. Solozhenko, N.M. Soboleva and V.V. Goncharuk, Water Res., 29, 2206 (1995).

7. W.Z. Tang and S. Tassos, Water Res., 31, 1117 (1997).

8. H.L. Zheng, Y.X. Pan and X.Y. Xiang, J .Hazard. Mater, 141, 457 (2007).

9. S.H. Lin, C.M. Lin and H.G. Leu, Water Res., 33, 1735 (1998).

10. W. Spacek, R. Bauer and G. Heisler, Chemosphere, 30, 477 (1995).

11. M. Muruganandham and M. Swaminathan, Dyes Pigments, 63, 315 (2004).

12. Y.W. Kang and K.-Y. Hwang, Water Res., 34, 2786 (2000).

13. J.H. Ramirez, F.J. Maldonado-Hódar, A.F. Pérez-Cadenas, C. MorenoCastilla, C.A. Costa and L.M. Madeira, Appl. Catal. B, 75, 312 (2007).

14. H. Xu, D.X. Zhang and W.G. Xu, J. Hazard. Mater., 158, 445 (2008). 